\title{
Editorial
}

Neuro

epidemiology

\section{Driving Your Recovery Post Stroke}

\author{
Valery L. Feigin \\ National Institute for Stroke and Applied Neurosciences, School of Public Health and Psychosocial Studies, \\ Faculty of Health and Environmental Sciences, AUT University, Auckland, New Zealand
}

The burden of stroke is increasing in each and every country of the world and the number of stroke survivors and people affected by stroke annually has already increased to a level (over 80 million stroke survivors and about 14 million new strokes annually) [1] that threatens the sustainability of the health system as a whole [2]. Globally, the burden of stroke in terms of an absolute number of people affected by stroke, who died from it or who have remained disabled has almost doubled the last 27 years (1990-2016) [1], and this trend is likely to continue due to the continuing pattern of ageing of the population, population growth and unfavourable trends in many stroke risk factors (especially overweight and diabetes) [3]. Even now in developed countries, only about one half of stroke survivors discharged from a hospital have access to and receive outpatient rehabilitation within the first few months after stroke onset $[4,5]$. In developing countries, many people with acute stroke are not hospitalised at all and only a small proportion of stroke survivors receive some rehabilitation [6-8].

In this situation, there is increasing recognition among stroke experts that the only practicable way to improve rehabilitation is self-management $[9,10]$. However, to improve recovery after a stroke and reduce the burden in stroke survivors, these interventions need to be in a format and the mode of delivery that allows them to be used by stroke survivors and their family members at any time, as long as required, in virtually any setting (e.g., home, rest-home etc.) with only minimum input from health professionals [11]. Such interventions should be based on the best available evidence and be culturally appropriate and affordable. Ideally, they should employ a role-model tutorial approach where most of the rehabilitation and stroke general care procedures are shown by lay people of different ages, sex and ethnicity/race in order that the viewers can associate themselves with these role models and say "If they can do it, then I can do it too."

However, to the best of our knowledge, until recently there were no such comprehensive evidence-informed role-model-based self-management programmes available anywhere in the world. Not anymore. The New Zealand Charitable Stroke Education Trust recently released a webpage (www.stroke.net.nz) where people can view and stream video clips of their choice for only a symbolic subscription fee. These video clips were taken from a series of stroke self-management DVDs developed by the Trust and endorsed by the World Federation of Neurore-

\section{KARGER}

(c) 2018 S. Karger AG, Basel 
habilitation and World Stroke Federation (currently World Stroke Organization) and reviewed by various experts/reviewers, including the International Journal of Stroke [12] and The Lancet Neurology [13]. Most recently these DVDs have been successfully tested in a multicentre proof-of-concept randomised controlled trial in 6 countries, and the intervention has proved highly acceptable [14], thus offering a new promising source of affordable self-rehabilitation programmes post stroke every single day all through the year. There is already a huge interest from a number of stroke organisations to use these training/educational materials for stroke recovery. The Trust is determined to make all these rehabilitation video clips available completely free of charge to as many countries as possible. Any organisation that would be willing to pay a reasonable licence fee to have these video clips freely available for streaming to their citizens at any time and frequency are welcome to contact the Trust (nzset@stroke.net.nz) to work out the logistics of these arrangements.

\section{References}

1 Institute for Health Metrics and Evaluation (IHME). GBD Compare Data Visualization. Seattle, IHME, University of Washington, 2016. http://vizhub.Healthdata.Org/gbd-compare (accessed June 1, 2018).

2 Feigin VL, Norrving B, George MG, Foltz JL, Roth GA, Mensah GA: Prevention of stroke: a strategic global imperative. Nat Rev Neurol 2016;12:501-512.

3 Feigin VL, Roth GA, Naghavi M, Parmar P, Krishnamurthi R, Chugh S, et al: Global burden of stroke and risk factors in 188 countries, during 1990-2013: a systematic analysis for the Global Burden of Disease Study 2013. Lancet Neurol 2016;15:913-924.

4 Hall P, Williams D, Hickey A, Brewer L, Mellon L, Dolan E, et al: Access to rehabilitation at six months post stroke: a profile from the action on secondary prevention interventions and rehabilitation in stroke (ASPIRE-S) study. Cerebrovasc Dis 2016;42:247-254.
5 Jan S, Essue BM, Glozier N, Lindley R, Li Q, Hackett ML: Are rehabilitation services following stroke accessed equitably in Australia?: findings from the psychosocial outcomes in stroke (POISE) cohort study. BMC Public Health 2013;13:884.

6 Mohd Nordin NA, Aziz NA, Abdul Aziz AF, Ajit Singh DK, Omar Othman NA, Sulong S, et al: Exploring views on long term rehabilitation for people with stroke in a developing country: findings from focus group discussions. BMC Health Serv Res 2014;14:118.

7 Pandian JD, Sudhan P: Stroke epidemiology and stroke care services in India. J Stroke 2013;15:128-134.

8 Yan LL, Li C, Chen J, Miranda JJ, Luo R, Bettger J, et al: Prevention, management, and rehabilitation of stroke in low- and middle-income countries. eNeurologicalSci 2016;2:2130.

9 Parke HL, Epiphaniou E, Pearce G, Taylor SJC, Sheikh A, Griffiths CJ, et al: Self-management support interventions for stroke survivors: a systematic meta-review. PLoS One 2015; 10:e 0131448.
10 Fryer CE, Luker JA, McDonnell MN, Hillier SL: Self-management programs for quality of life in people with stroke. Stroke 2016; 47:e266-e267.

11 Jones KM, Bhattacharjee R, Krishnamurthi R, Blanton S, Theadom A, Barker-Collo S, et al: Methodology of the stroke self-management rehabilitation trial: an international, multisite pilot trial. J Stroke Cerebrovasc Dis 2015;24: 297-303.

12 Norrving B: Media review: stroke education successfully goes DVD. Int J Stroke 2007;2:137.

13 Hobbs S: How to cope with stroke, by those who do. Lancet Neurol 2007;6:587.

14 Jones KM, Bhattacharjee R, Krishnamurthi R, Blanton S, Barker-Collo S, Theadom A, et al: Determining the feasibility and preliminary efficacy of a stroke instructional and educational DVD in a multinational context: a randomized controlled pilot study. Clin Rehabil 2018:0269215518777565. 